\title{
Correction to: Effect of 25-hydroxyvitaminD on Helicobacter pylori eradication in patients with type 2 diabetes
}

Bin Huang · Shengju Yan · Chao Chen · Shandong Ye

Published online: 9 January 2019

(c) The Author(s) 2018

\section{Correction to:}

Wien Klin Wochenschr 2018

https://doi.org/10.1007/s00508-018-1416-y

The original version of this article unfortunately contained a mistake.

The spelling of Shengju Yan's name was incorrect. We apologize for this mistake.

The original article has been corrected. 